\title{
IOWATER: A Freshman Research Initiative for geology and meteorology majors
}

\section{CINZIA CERVATO ${ }^{1}$, DAVE FLORY ${ }^{1}$,}

WILLIAM GALLUS ${ }^{1}$

AND ELIZABETH SANDQUIST ${ }^{2}$

PRESENTED BY THERESA HALLIGAN ${ }^{1}$

1GEOLOGICAL \& ATMOSPHERIC SCIENCES

${ }^{2}$ GENETICS, DEVELOPMENT \& CELL BIOLOGY 


\section{ISU Freshman Research Initiative}

- Started in 2015 with HHMl funding

- Simplified version of FRI at University of Texas, Austin

- Undergraduate peer mentors

- Part-time graduate TAs

- Thirteen streams/courses from 9 disciplines and three colleges

○ SETUP: Safe \& Efficient Transportation

- Dancing for Parkinson's

- Stem Cells for Neuroregeneration

- Semester or half-semester experiences

o Between 5 and 35 students in each stream 


\section{Earth Wind \& Fire Learning Community}

- First-year meteorology and geology students

- Field trip in August for new students, peer mentors, and faculty

- Fall and spring 1-credit orientation courses

- Fall covers introduction to university, academic services, and department

- Spring focuses on resilience and professionalism with research experience 


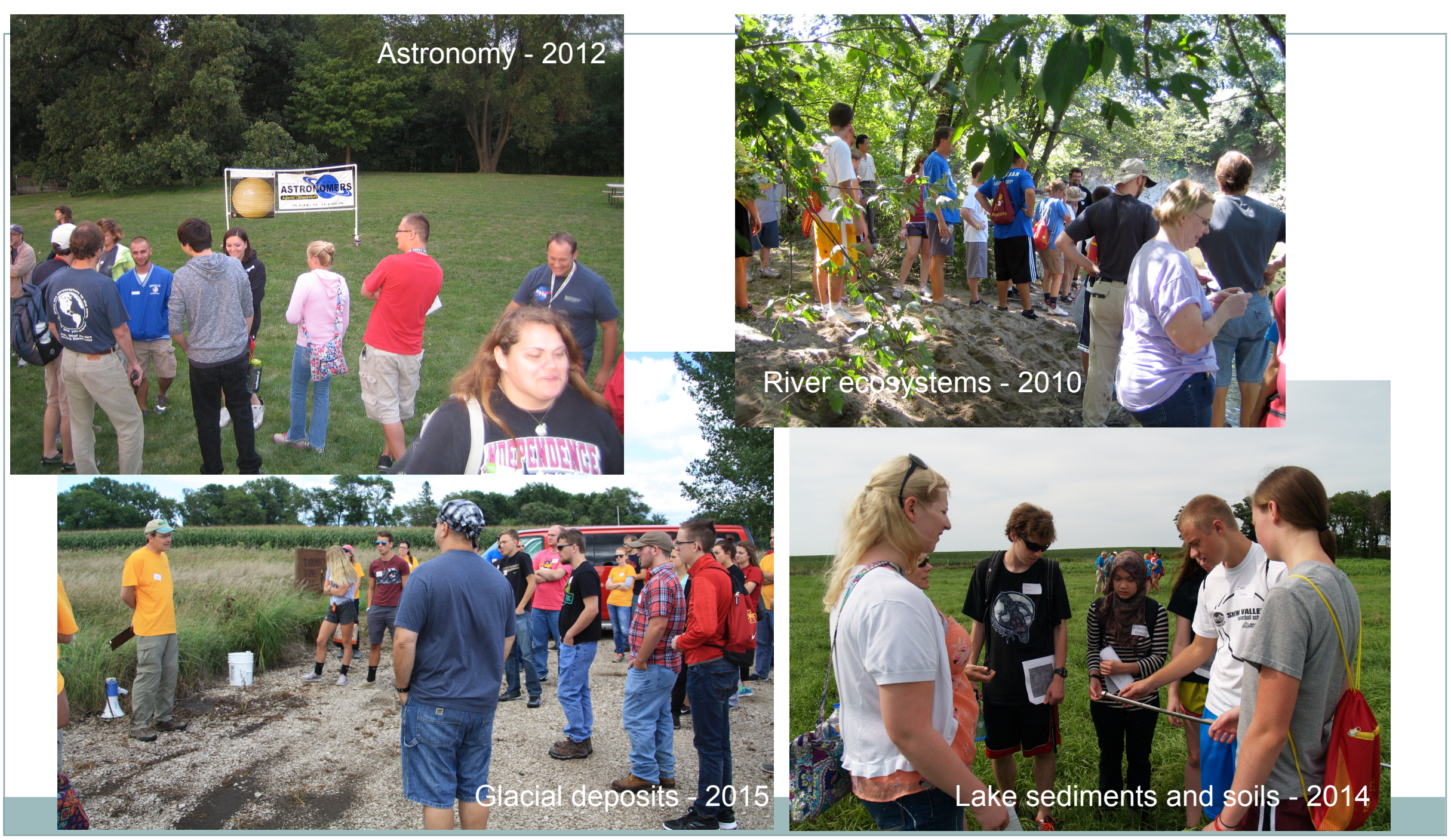




\section{lowa DNR - IOWATER}

- Volunteer water quality monitoring since 1998

- Network of easily accessible sites along streams in lowa

- Developed protocols for stream habitat and physical/chemical assessment; provided starter kits

- Results stored in database

- Lack of funding reduced and eventually stopped data collection in 2015

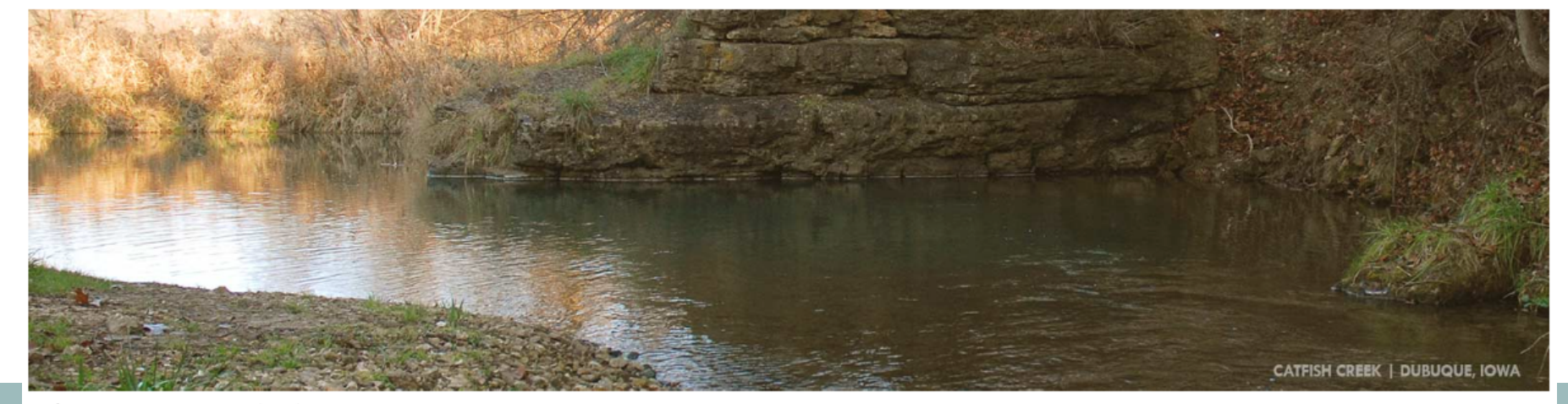




\section{IOWATER FRI experience}

- Adopted IOWATER assessment protocols

- Assembled starter kits

$\circ \mathrm{pH}$, nitrate/nitrite, and chloride test strips

o Transparency tubes

o Meter sticks

- Bailer and rope

- Learning community funds used for consumables - costs are kept low

- Offered spring 2016 and 2017 to class of approximately 20 students 


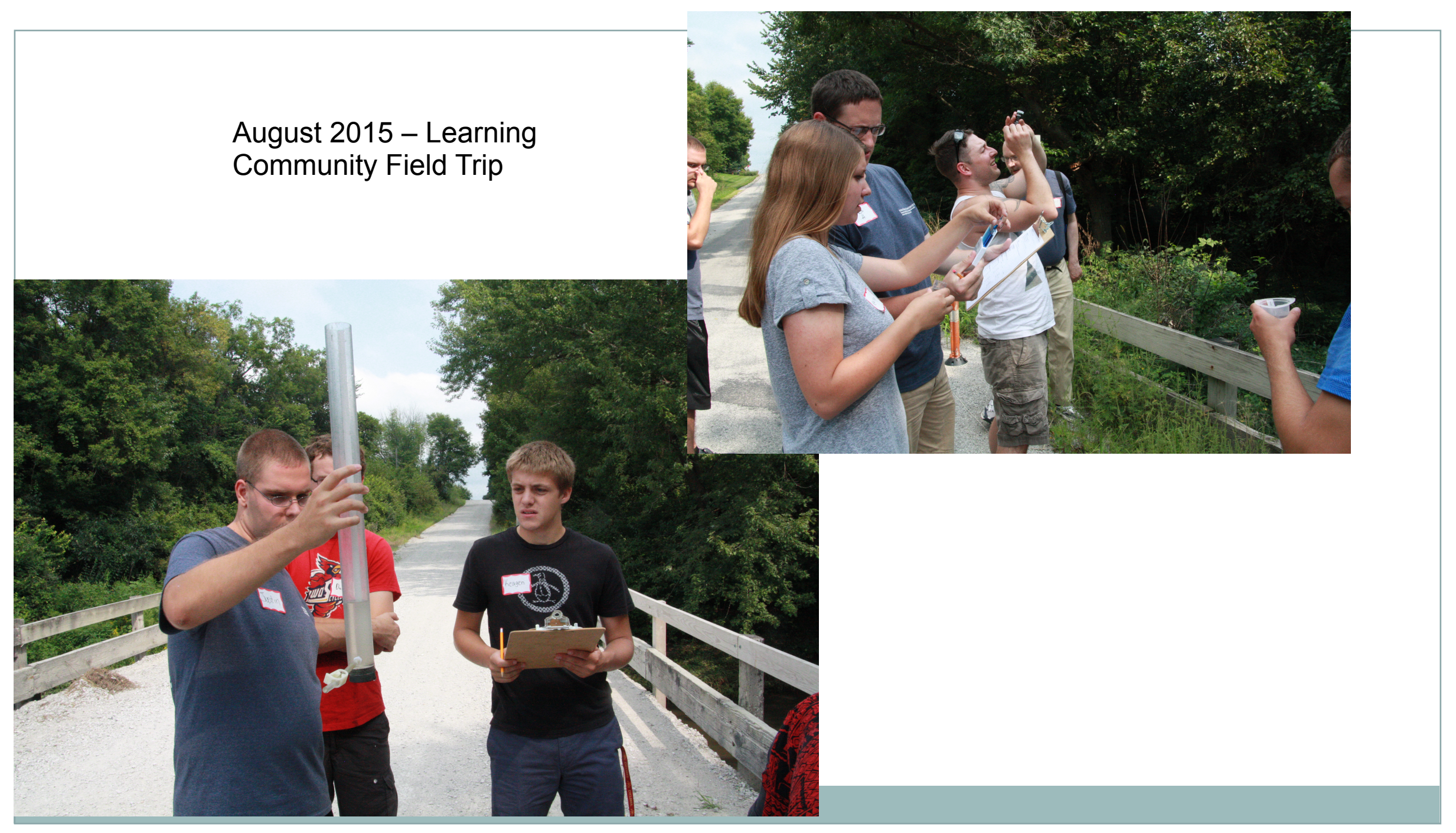




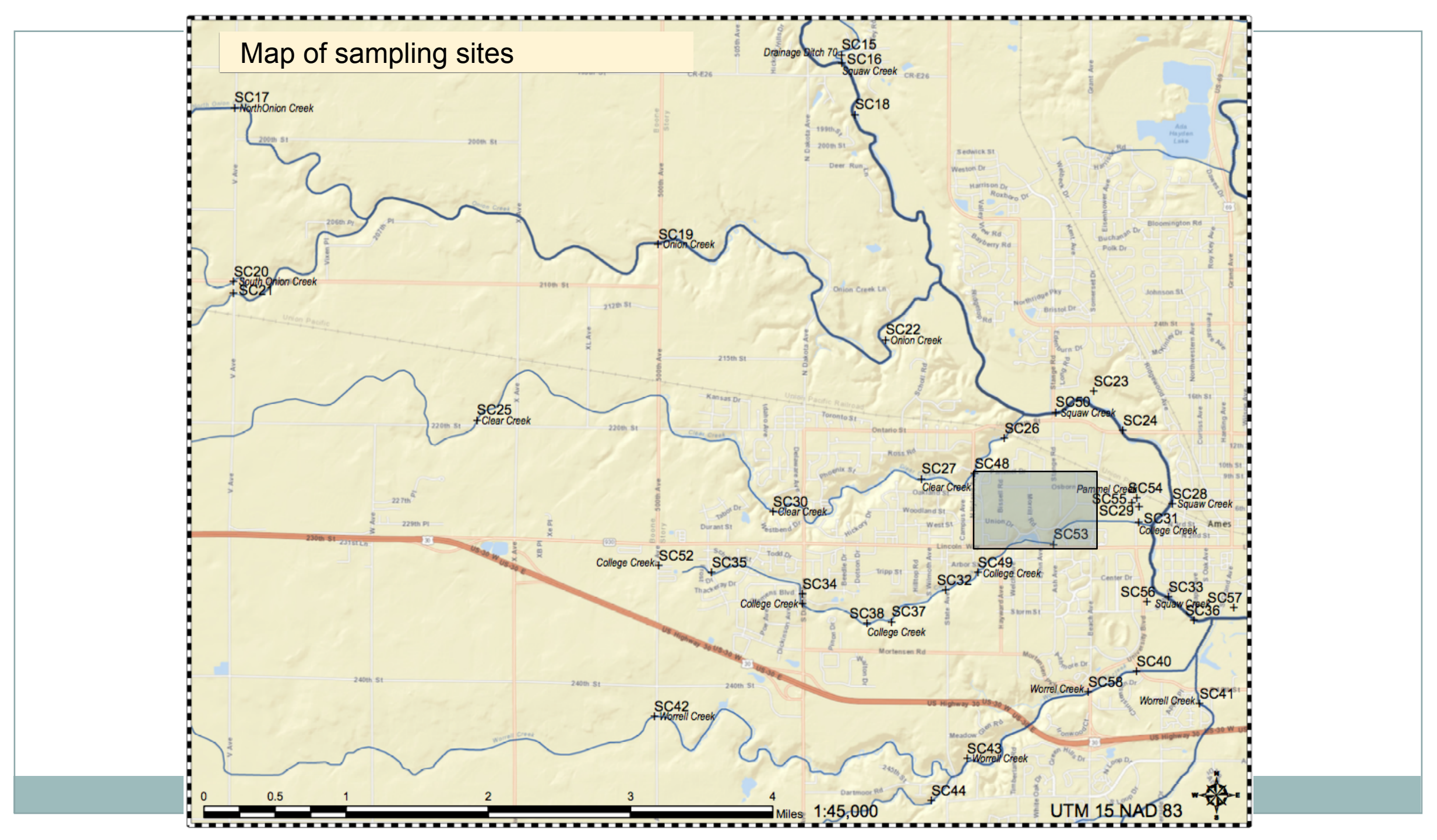




\section{IOWATER Research Experience Layout}

- Learning outcomes

- Students in small teams will study water quality and stream discharge near Ames

- Students will present their research results at the FRI Poster Symposium

- Learning goals

- Locate, download, and perform simple statistical analysis on web-based data (USGS stream discharge from gauges, weather data from lowa Environmental Mesonet)

- Plot daily precipitation and stream discharge data over a 3-month period

- Analyze water samples in the field using established protocols to answer specific research question

- Compare results with historical data from IOWATER database and data from City of Ames Water Treatment Plant

- Interpret water quality results within the framework of stream discharge and precipitation 


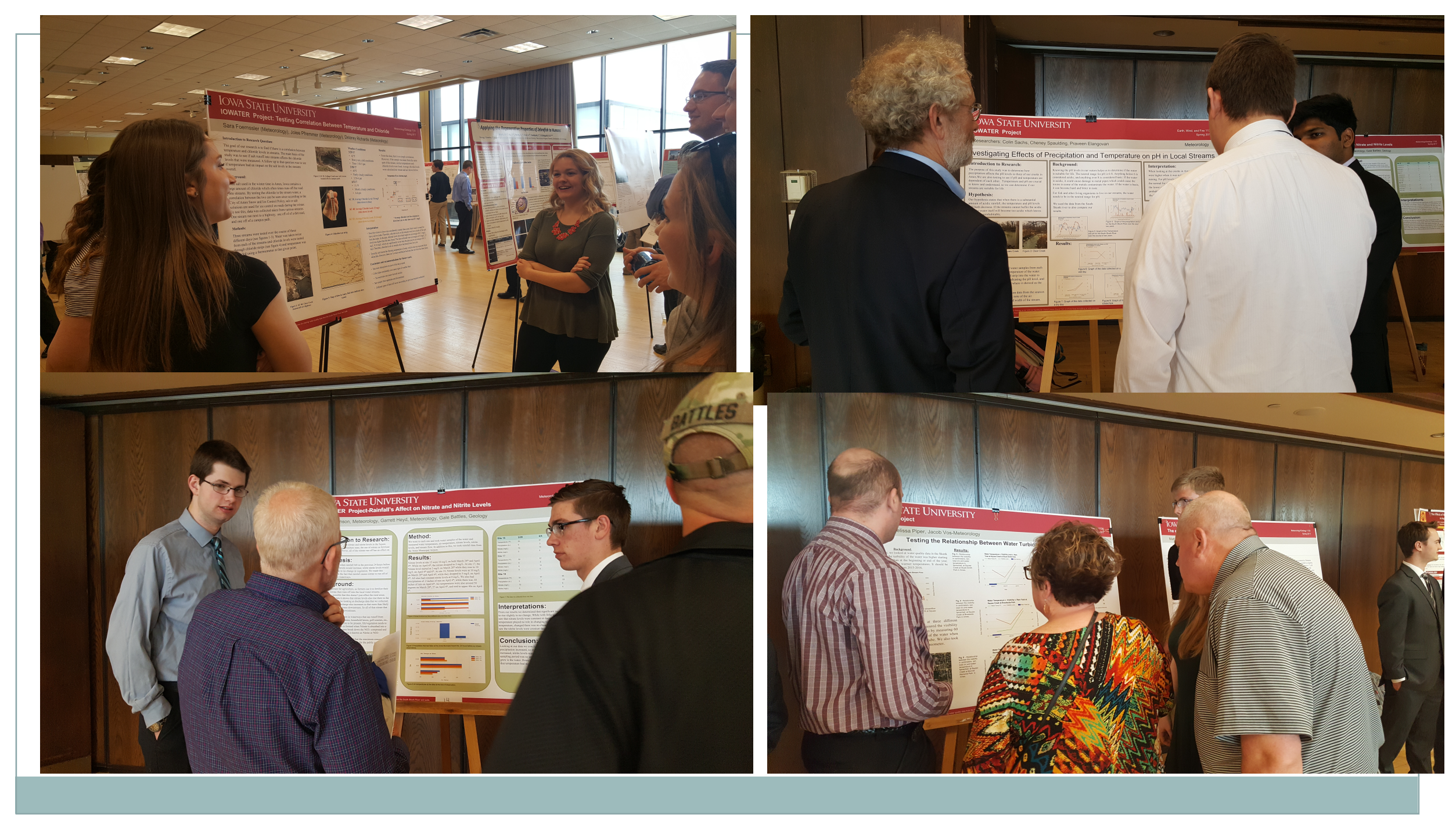




\section{FRI Assessment}

- Undergraduate Research Student Self-Assessment (URSSA $)^{1}$

$\circ$ Thinking and working like a scientist

○ Personal gains

$\circ$ Gains in skills

○ Assessment of research experience

- STEM retention

○ All students from spring $2016(\mathrm{~N}=9)$

- 89\% of students from spring 2017 ( $\mathrm{N}=18)$

1 Weston, T. J., and S. L. Laursen. 2015. "The Undergraduate Research Student Self-Assessment (URSSA): Validation for Use in Program Evaluation." CBE Life Sci Educ 14 (3). doi: 10.1187/cbe. 14-11-0206 


\section{Thinking like a scientist - IOWATER (N=16)}

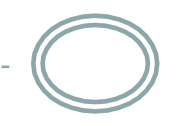

\section{IOWATER}

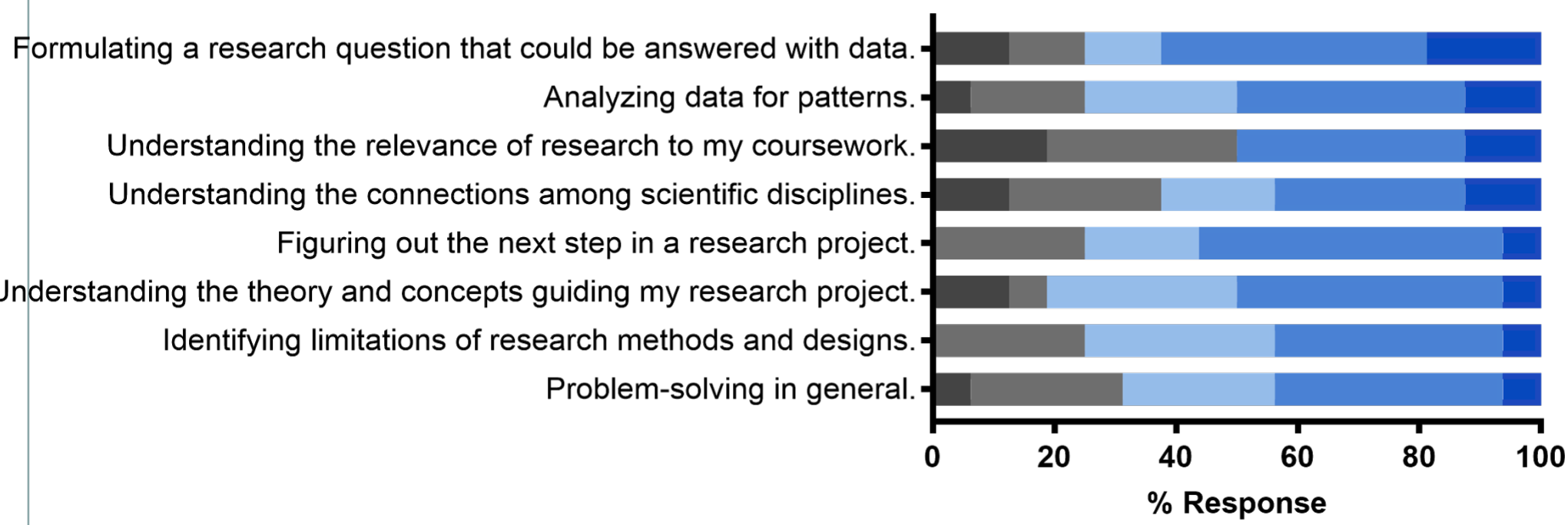

- great gain

good gain

moderate gain

a little gain

no gains 


\section{Personal gains - IOWATER $(\mathrm{N}=12)$}

(

Fraction of total of IOWATER

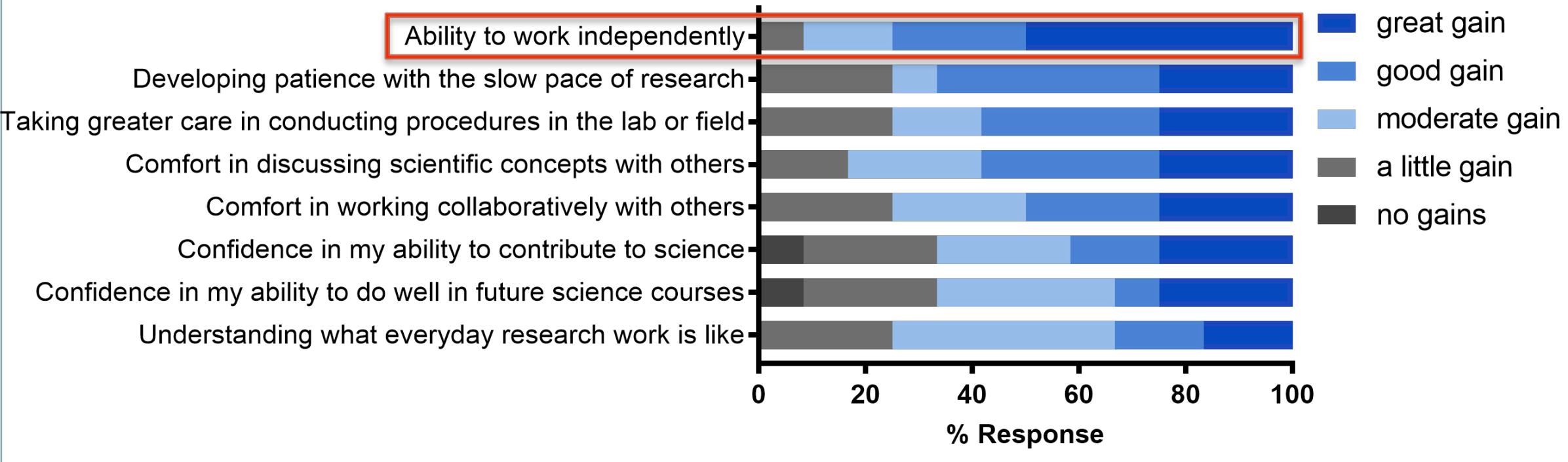




\section{Skills - IOWATER $(\mathrm{N}=12)$}

\section{Fraction of Total of IOWATER}

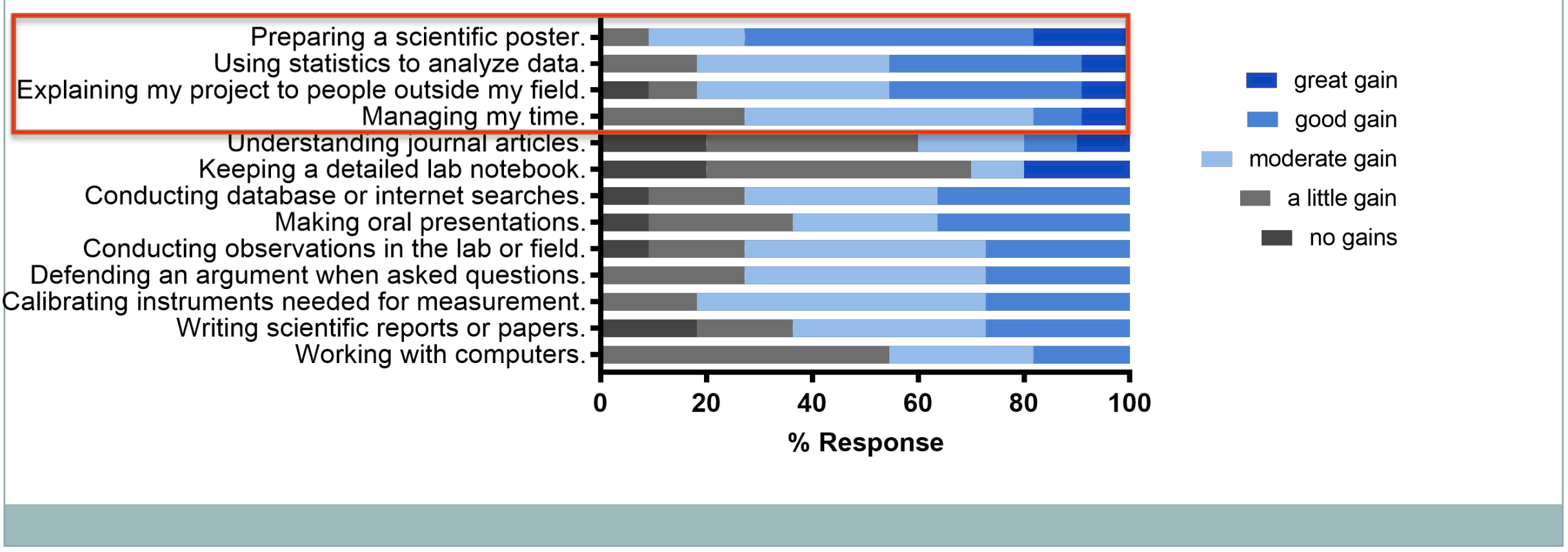




\section{Student Comments on Research Experience}

These questions ask about your research experience. Please comment on any of these aspects.

I felt like I worked well with my peers and the research mentors did a good job providing help and advice. (4/5)

Did you make other gains from doing research that we didn't mention? If so, please briefly describe these.

It helped me work well with others on a research project which I need to do in the future. (3/4) 


\section{Student Comments on Future Plans}

Please state your intended degree and, compared to your intentions BEFORE doing research, HOW LIKELY YOU ARE NOW to enroll in a graduate program leading to an advanced degree.

Geology. I'm very likely to enter a graduate program, I wanted to before but I want to more now. (10/11)

How did your research experience influence your thinking about future career and graduate school plans? Please explain.

It allowed me to get a glimpse of what my senior thesis would be like and how to conduct research in a professional way.

It helped me understand future science research projects that I may undertake.

It helped me learn how to conduct a good experiment and I believe this will help me for my future career.

It made me think more about what I like and what I don't which cancelled some things out for me. (6/13 positive, $7 / 13$ neutral) 


\section{Summary}

- Introducing freshmen to authentic research has a positive effect on their skills, appreciation of their major, and future plans

- Embedding a research experience in an orientation course/learning community is practical and ensures sustainability

- A project created around water quality and surface water recharge is easy to implement and low cost

- Implementing an assessment/revision loop allows to tune activity to student needs and interests 


\section{Questions?}

For more details about the implementation of a freshman research initiative, email Cinzia Cervato cinzia@ iastate.edu

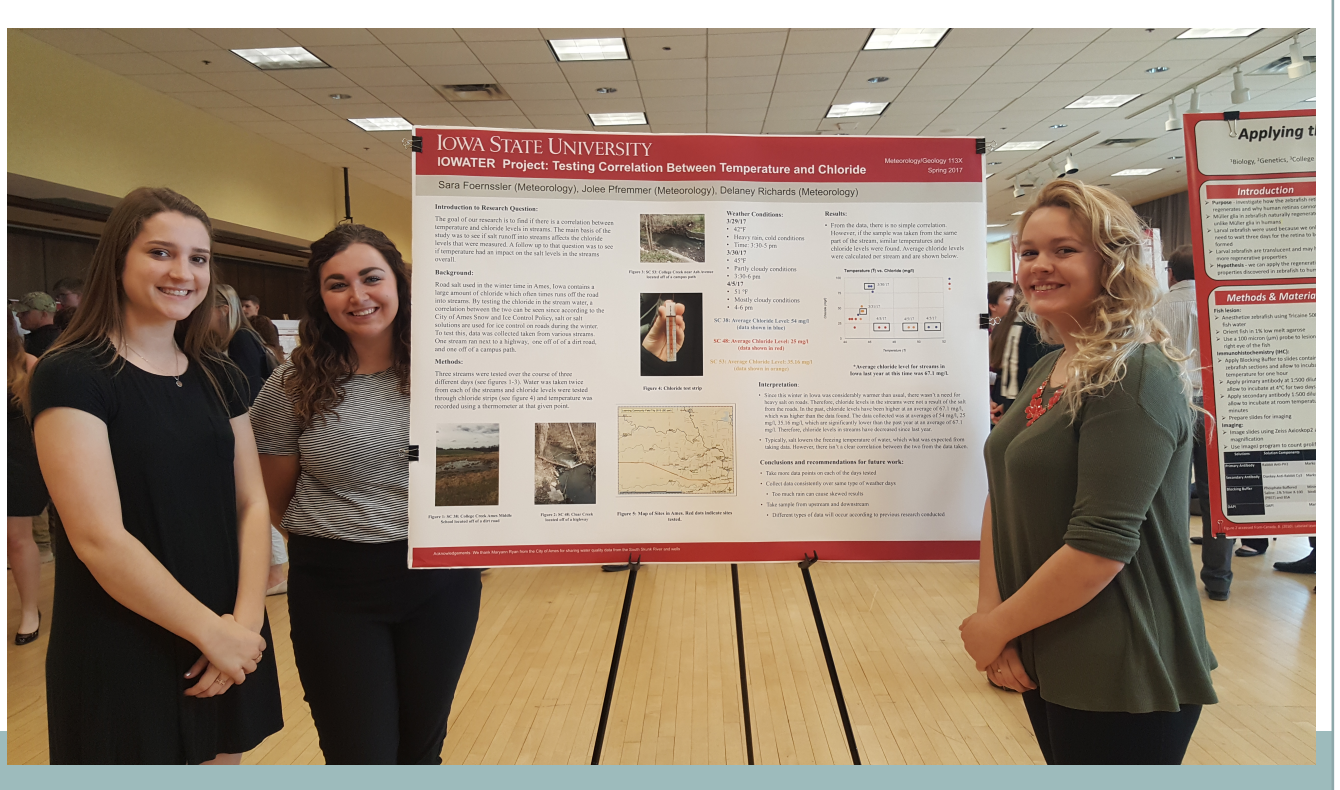

